\title{
Educação Patrimonial no Museu Municipal Parque da Baronesa como possibilidade de Turismo Cidadão. Pelotas/RS
}

\author{
Educación sobre el Patrimonio en el Museo Municipal Baronesa \\ Parque como posibilidad de Turismo Ciudadano. Pelotas / RS
}

\author{
Heritage Education at Museu Municipal Parque da Baronesa as a \\ possibility for Citizen Tourism. Pelotas/RS
}

\author{
Dra. Dalila Rosa Hallal ${ }^{1}$ \\ Dra. Dalila Müller ${ }^{2}$
}

\begin{abstract}
Resumo
Este estudo tem como objetivo analisar as ações de Educação Patrimonial do Museu Municipal Parque da Baronesa - MMPB enquanto uma prática de turismo cidadão. A valorização das atividades museológicas, na área educativa, vem recebendo uma atenção especial nos últimos anos. O papel principal do museu, na sociedade, é informar e apresentar a herança cultural de um povo. É de extrema relevância incentivar a criação de espaços que promovam diálogos que contestem, mostrem, despertem novas atitudes e repassem informações ao turista cidadão a respeito das transformações e manifestações culturais e sociais ocorridas em seu ambiente. Inicialmente descrevemos a trajetória da família Antunes Maciel e do Museu Municipal Parque da Baronesa. Para isso, foi realizada pesquisa documental em jornais disponíveis no acervo do museu e pesquisa de campo através da observação e de entrevista. Através da analise dos dados coletados identificou-se diversas ações de educação patrimonial, realizadas pelo MMPB, tais como, visitas guiadas, folders, cartilha pedagógica, dentre outros. Tais ações podem ser entendidas como práticas que promovem a experiência do estranhamento, configurando-se como turismo cidadão.
\end{abstract}

Palavras-chave: Educação Patrimonial. Museu Municipal Parque da Baronesa. Turismo Cidadão. Pelotas.

\begin{abstract}
This study aims to analyze the Heritage Education actions at Museu Municipal Parque da Baronesa - MMPB as citizen tourism practice. The appreciation of museological activities in the educational field has been given special attention in recent years. The major role museums play in society is that of presenting the cultural heritage of a people. It is extremely important to encourage the creation of spaces that promote dialogues that contest, show, and encourage new attitudes and pass on information to citizens about the tourist and cultural transformations and social events that have occurred in their environment. We describe the trajectory of the Antunes Maciel family and of Museu Municipal Parque da Baronesa. To do so, we conducted documentary research on newspapers available at museum collections and a field research through observations and interviews. Through the analysis of the collected data we identified several actions related to heritage education carried out by MMPB, such as guided tours, brochures, educational booklets, among others. Such actions can be understood as practices that promote the experience of strangeness, thus functioning as citizen tourism.
\end{abstract}

\footnotetext{
${ }^{1}$ Doutora em História; Universidade Federal de Pelotas - UFPel; Pelotas, Rio Grande do Sul, Brasil. dalilahallal@gmail.com

${ }^{2}$ Doutora em História; Universidade Federal de Pelotas - UFPel; Pelotas, Rio Grande do Sul, Brasil. dalilam2011@gmail.com
} 
Keywords: Heritage Education. Museu Municipal Parque da Baronesa. Citizen Tourism. Pelotas.

Este estudio tiene como objetivo analizar las acciones de educación sobre el patrimonio del do Museu Municipal Parque da Baronesa - MMPB como una práctica de turismo de los ciudadanos. La valoración de las actividades museológicas en el campo de la educación, ha recibido especial atención en los últimos años. El papel principal del museo en la sociedad es el de informar y presentar el patrimonio cultural de un pueblo. Es extremadamente importante para fomentar la creación de espacios que promueven diálogos ese concurso, espectáculo, despiertan nuevas actitudes y transmitir la información a los ciudadanos sobre las transformaciones turísticos y culturales y eventos sociales que se han producido en su entorno. Se describe la trayectoria de la familia Antunes Maciel y de Museu Municipal Parque da Baronesa. Para ello, se realizó una investigación documental sobre los periódicos disponibles en colecciones de museos y la investigación de campo a través de la observación y la entrevista. A través del análisis de los datos recogidos se identificó varias acciones de educación patrimonial, llevado a cabo por MMPB tales como visitas guiadas, folletos, folleto educativo, entre otros. Tales acciones pueden ser entendidas como prácticas que promueven la extrañeza de la experiencia, convirtiéndose en un turismo ciudadano.

Palabras clave: Educación sobre el patrimonio. Museu Municipal Parque da Baronesa. Turismo Ciudadano. Pelotas.

\section{Introdução}

O MMPB (Museu Municipal Parque da Baronesa), fundado no ano de 1982, tem por temática retratar os usos e os costumes da elite pelotense do século XIX e início do século XX. Aberto há vinte e oitos anos, já possui uma importância histórica para a cidade de Pelotas visto que sua origem contextualiza-se na época do apogeu econômico e cultural deste município, sendo este proveniente das charqueadas que aqui se instalaram no século XVIII.

Durante todo o século XIX a cidade de Pelotas se desenvolveu economicamente em função da atividade charqueadora, destacando-se pela sua economia, mas também pela vida social e cultural. Atualmente, alguns espaços construídos nesse período passaram por um processo de mudança e configuram-se como patrimônio da cidade, sendo utilizados como espaços públicos de lazer. Dentre eles, destaca-se o Museu Municipal Parque da Baronesa MMPB que nos remete a essa época de auge em que Pelotas viveu. Atualmente possui dois prédios e uma extensa área verde, destinado ao lazer cultural, onde são encontrados jardins, bosques e lagos que embelezam a paisagem do bairro Areal, aberto ao publico diariamente.

Atualmente os museus não são somente espaços em que se guarda, conserva, expõe e comunica memórias, mas também instigam, despertam interesse e relativizam lembranças de forma a gerar novos questionamentos, proposições e representações a seus visitantes. Tornando o indivíduo parte integrante daquele espaço, fazendo com que o morador da localidade vivencie, através da educação patrimonial, a experiência do estranhamento e realize o turismo cidadão.

O presente artigo tem como objetivo analisar as ações de educação patrimonial do Museu Municipal Parque da Baronesa - MMPB enquanto uma prática de turismo cidadão. 
Trata-se de uma pesquisa de cunho qualitativo que busca investigar as práticas de educação patrimonial para o turista cidadão no Museu Municipal Parque da Baronesa. Para isso, foi realizada pesquisa documental em jornais disponíveis no acervo do museu e pesquisa de campo realizada a partir de entrevista e observações. Enfrentamos o desafio de manter vivos não somente o patrimônio arquitetônico e cultural, como também o acesso a todos à história de sua cidade e aos espaços públicos de lazer.

O Museu Municipal Parque da Baronesa se apresenta como espaço de educação patrimonial onde a (re)significação dessa experiência, mediante as práticas de lazer e turismo cidadão, transformam a relação do habitante com a cidade e com a vida que a anima.

\section{Museu Municipal Parque da Baronesa}

Para falarmos do Museu Municipal Parque da Baronesa - MMPB se faz necessário apresentar um pouco da trajetória da Família Antunes Maciel, família que construiu e morou no local enquanto era utilizado para residência.

O terreno em que hoje está localizado o Solar ${ }^{3}$ da Baronesa foi comprado em 1863, pelo Coronel Aníbal Antunes Maciel, para presentear seu filho Aníbal Antunes Maciel Junior, em virtude de seu casamento com Amélia Fortunata Hartley de Brito (SCHWANZ, 2011). Destaca-se o fato de que neste período, o centro urbano da cidade era afastado da chácara, portanto era possível ser comparada a uma casa de campo ou um Solar.

Os Barões dos Três Serros, Aníbal e Amélia, casaram-se em 1864, e logo se estabeleceram na chácara. Amélia era filha de ingleses de alto poder, sócios do Banco de Londres situado no Rio de Janeiro e estavam na cidade para abrir uma filial. Esta foi a primeira de três gerações que habitou a residência (MUSEU MUNICIPAL PARQUE DA BARONESA, 2016).

Em 1884 Aníbal Antunes Maciel, que era charqueador, recebe o título de Barão de Três Serros, pois alforriou seus escravos em Pelotas, antes mesmo da assinatura da Lei Áurea (PAULA, 2008). O título de Barão era concedido a importantes nomes da sociedade por "serviços" e "grandes feitos" que de alguma forma beneficiavam o governo imperial no Brasil (SCHWANZ, 2011).

A família costumava passar os invernos no Rio de Janeiro, período de abril a outubro, e ficar em Pelotas no verão, de novembro a maio. Uma pratica comum entre a elite pelotense, que aos invernos buscavam cidades com clima agradável.

\footnotetext{
${ }^{3}$ Nome utilizado para uma casa antiga, de grande luxo, relativo à sua época.
} 
Porem, do lucro que viria com o baronato, Annibal não pode gozar durante muito tempo, pois morreu três anos após receber o título, aos 49 anos de idade (SCHWANZ, 2011).

Da união dos Barões, foi concebido um total de quatorze filhos (PAULA, 2008) sendo que destes apenas oito chegaram à idade adulta.

Dentre eles, Sinhá - assim chamada carinhosamente por receber o mesmo nome da mãe - a filha mais velha da Baronesa, uniu-se em matrimonio em 1890 com o seu primo Lourival Antunes Maciel (PAULA, 2008) sendo a segunda geração que habitou o solar após a ida permanente da Baronesa para o Rio de Janeiro.

Sinhá e Lourival tiveram o total de doze filhos, dos quais seis faleceram ainda bebês, não chegando à idade adulta (MUSEU MUNICIPAL PARQUE DA BARONESA, 2016). A terceira geração a habitar o Solar foi à filha mais nova de Sinhá, neta da Baronesa, Déa Antunes Maciel.

Déa foi a ultima moradora da casa, permanecendo na mesma até meados de 1960. Posteriormente usava a casa apenas nos verões, passando a maior parte do tempo no Rio de Janeiro (MUSEU MUNICIPAL PARQUE DA BARONESA, 2016). Em suas últimas vindas a Pelotas, Déa não se hospedou no Casarão, em virtude de o mesmo encontrar-se em nível critico de deterioração. Ficava então hospedada na casa construída em 1929 na entrada do Parque, para seu irmão Delmar Antunes Maciel e sua família (SCHAWNZ, 2011).

Logo, toda família Antunes Maciel fixou residência no Rio de Janeiro, deixando a casa abandonada durante dez anos. Com o distanciamento da família surgiram boatos de que o Parque poderia ser vendido e transformado em loteamento, sendo o prédio demolido. Especulações a respeito da propriedade saiam com frequência em manchetes nos jornais da cidade.

Déa Antunes Maciel é citada na reportagem do jornal Diário popular (07.07.1968, s/p) onde a mesma diz que acredita que o Solar não será demolido e que a família ainda não tem um ponto de vista formado sobre o futuro da chácara.

Na mesma reportagem aparece o papel da Prefeitura Municipal que diagnosticou a casa da Baronesa como equipamento social dentro do Plano Diretor de 1968, mencionando a seguinte resolução: "Recomenda-se o estabelecimento de convenio entre a administração municipal e seus proprietários no sentido de proporcionar aos estudantes e população em geral, a possibilidade de visitação a este patrimônio artístico da cidade" (MONTONE 2011, p. $30)$.

Em 25 de novembro de 1970, o mesmo jornal trouxe outra vez a questão da venda da propriedade, demonstrando preocupação por parte do poder publico, em especifico do 
Conselho Municipal de Turismo, com o destino que poderia ser dado a este espaço (MONTONE 2011, p. 30).

Em 1978, a antiga residência - datada de 1863, pertencente aos Barões de Três Cerros - e o parque, em seu entorno, foram doados pela família Antunes Maciel ao município de Pelotas, incluindo um conjunto de elementos paisagísticos, de gosto romântico, aos moldes do século XIX.

No documento de doação, foi adicionada uma clausula cuja condição era de que o Parque e o prédio fossem transformados em espaços abertos ao publico. A doação de sete hectares de terra dos Antunes Maciel também foi noticia nos jornais com o titulo "Baronesa, recebida por doação, é agora, do patrimônio histórico" (DIÁRIO POPULAR, 03.07.1978, $\mathrm{s} / \mathrm{p})$.

A inauguração do MMPB ocorreu em 25 de abril de 1982. O jornal Correio do Povo discorre sobre a inauguração e ressalta que "ao restaurar o Parque da Baronesa, a prefeitura devolve a cidade um pouco de sua vida e memória" (CORREIO DO POVO, 27.04.1982, s/p).

Neste período, a administração municipal estava sob os cuidados do prefeito Irajá Rodrigues, que, de acordo com o mesmo jornal, "desde que assumiu a prefeitura, procurou oferecer um trabalho vinculado diretamente com o passado cultural e tradicional da cidade. Diante disso, muitas foram às lutas para tombamentos de prédios considerados históricos, obtenções de recursos para restauração e doações de prédios ao município" (CORREIO DO POVO, 27.04.1982, s/p).

De acordo com o Decreto Municipal No 3.069, de 15 de abril de 1992, que deixou a Fundação de Cultura, Esporte, Lazer e Turismo ${ }^{4}$ do município responsável pelo MMPB, em seu artigo terceiro definiu que: "a entidade terá como objetivo a criação de um espaço cultural destinado a coletar, preservar e expor os bens que constituem o acervo do museu, promovendo atividades com vistas a sua difusão, caracterizando-o como um espaço didático e como atração turística" (MONTONE, 2011, p.32).

Três anos após a sua inauguração, o MMPB foi tombado 5 como patrimônio histórico municipal, e nos dias de hoje é extremamente importante, sendo um dos pontos de referencia turística da cidade de Pelotas, fazendo parte da promoção turística oficial da cidade que é representada através de folders, sites, divulgação via redes sociais, jornais locais, entre outros meios de comunicação.

\footnotetext{
${ }^{4}$ A Fundação de Cultura, Esporte, Lazer e Turismo tinha o objetivo de estimular, desenvolver e coordenar as atividades culturais, de esporte, lazer e turismo do município.

5 Tombado pelo Conselho Municipal do Patrimônio Histórico e Cultural em 3 de julho de 1985, aprovado pela lei $\mathrm{n}^{\circ} 2.708$.
} 

e-ISSN 2016/Atual: 2525-7870 | e-ISSN 2015/2016: 2447-018X

Além da casa principal, onde está instalado o Museu, existe um sobrado construído na década de 1930, em uma das entradas do Parque para um dos filhos de Sinhá. Em torno das casas encontra-se um jardim de modelo francês com chafariz, rodeado de bancos e canteiros simétricos, com um extenso gramado, contendo brinquedos infantis (balanço, gangorra e escorregador), uma gruta construída com pedras de quartzo, canaletes, ponte, ilha, um bosque com dois pequenos lagos. Atrás do prédio do museu também existe uma torre, chamada de casa de banho.

\section{Educação Patrimonial no Museu Municipal Parque da Baronesa como possibilidade de Turismo Cidadão.}

O museu tem um papel importante de colaborar com a difícil tarefa de explicar o Brasil e assim ajudar a entender e respeitar os que são diferentes de nós. Bruno (1996), em sua obra, também ressalta a importância dos museus para a compreensão do que somos.

O museu brasileiro tem contribuído para melhor compreensão deste universo caleidoscópio que envolve o 'meio' e a 'raça' deste território e desta nação, serviram em alguns momentos como expressão de um projeto nacional, e tem demonstrado a multiplicidade de formas e cores que na base dos distintos processos criativos que aproximam e misturam as influências nativas, africanas e europeias. Cabe destacar, ainda, que os Museus desse país nos têm ajudado a compreender o que somos, a conhecer a Ciência que produzimos e a arte que elaboramos, da mesma forma, estas instituições registram nossas fronteiras geográficas, sinalizam em direção à contribuição dos imigrantes e nos permitem conhecer a longevidade dos nossos povos. (BRUNO, 1996, p. 12)

Desse modo, os museus assumem o papel de poderosos meios educativos ao alcance da atividade turística e recreacional. Geralmente os museus são localizados em prédios também de valor histórico, o que acaba sendo mais um atrativo.

Neste contexto afirma Vasconcellos (2006):

O museu é algo muito mais que um mercado de tempo livre, posto que trata de preservar traços da memória da humanidade para que as gerações presentes e futuras possam deleitar-se com o gozo e o aprendizado de sua contemplação. (VASCONCELLOS, 2006, p. 37)

O museu é um espaço social do saber e do fazer, das historias, das memórias e das identidades. Desde a criação da Política Nacional de Museus, em 2003, e com um auxilio ainda maior após a criação do Instituto Brasileiro de Museus (IBRAM), em 2009, podemos dizer que os órgãos públicos responsáveis por estas instituições não tem medido esforços no sentido de fortalecer este setor. A nova autarquia vinculada ao Ministério da Cultura (MinC) 
sucedeu o Instituto do Patrimônio Histórico e Artístico Nacional (IPHAN) nos direitos, deveres e obrigações relacionados aos museus federais.

Com o aumento de museus no mundo e no Brasil, o papel educacional dos mesmos se intensificou, levando estes locais a se modificarem ou criarem táticas para promover a comunicação com o publico.

A função educacional do museu, segundo Horta (1991), é apresentar ao individuo o patrimônio cultural de que é herdeiro e da sua capacidade de utiliza-lo conceituando educação patrimonial como "o ensino centrado no objeto cultural, na evidencia material da cultura". Para Horta "a educação patrimonial não se refere apenas aos objetos do passado, mas igualmente aos do cotidiano, do presente, aos que estão sendo criados pelo homem no exercício de sua humanidade" (HORTA, 1991, p 12).

A Educação Patrimonial consiste em provocar situações de aprendizado sobre o processo cultural e ambiental e, a partir de suas manifestações, despertar no participante o interesse em resolver questões significativas para sua própria vida pessoal e coletiva. Tem como objetivo basear-se no esforço em auxiliar a comunidade local na elaboração do conhecimento histórico, cultural e ambiental, na investigação da realidade, refletindo a respeito de sua ligação com um passado mais distante, buscando compreender a historicidade das representações culturais, ou seja, um ensino voltado para sujeitos históricos deve propiciar um conhecimento mais amplo da realidade em que vivem.

Desta forma, a Educação Patrimonial em suas formas de mediação, possibilita a interpretação dos bens culturais e naturais, tornando-se um instrumento importante de promoção e vivência da cidadania. Consequentemente, gera a responsabilidade na busca, na valorização e na preservação do patrimônio (HORTA, 2005).

Horta (2005, p. 2) considera que "o conhecimento crítico e a apropriação consciente por parte das comunidades e indivíduos do seu 'patrimônio' são fatores indispensáveis no processo de preservação sustentável desses bens, assim como no fortalecimento dos sentimentos de identidade e cidadania".

Para Alencar (1987) é a educação patrimonial que aponta as bases em que o trabalho educativo dos museus pode ser desenvolvido, e este trabalho implica lidar com a mudança de atitudes relacionadas ao patrimônio cultural, envolvendo mais o sensível e o emocional. No entanto, é necessário que as noções de patrimônio sejam abordadas desde a educação infantil para que as pessoas, ao chegarem a uma instituição como um museu, tenham uma visão mais critica entre o passado e o presente e para que, como seres humanos, se identifiquem junto ao contexto em que estão inseridos, adquirindo conhecimentos de preservação e sustentabilidade. 
Museus são lugares para a livre troca de ideias, é o espaço onde aluno e professores cumprem o mesmo papel de descobridores, é um ambiente de descoberta. Desempenhando a função educativa, os objetos expostos deixam de ser a história e tornam-se um meio de contala. Desse modo o museu pode e deve ser usado como processo educacional, que cumpre com a ação cultural e educativa no âmbito da educação não formal e informal ${ }^{6}$. Estas ações não estão atribuídas somente a atividades relacionadas e desenvolvidas para alunos e professores, mas podem ser percebidas desde o momento em que é criado o roteiro de uma exposição, na elaboração de etiquetas e textos explicativos que despertem a reflexão, o questionamento e as criticas (SANDER, 2006).

A instituição museológica, por meio de sua feição pedagógica, pode oferecer uma gama de experiências culturais significativas. Assim, os programas educativos de diversos espaços museais precisam buscar uma melhor utilização dos recursos de aprendizagem em situações informais, priorizando as novas demandas socioeducacionais e valorizando o museu como espaço, ao mesmo tempo, de educação e de lazer (HERMETO; OLIVEIRA, 2009). Dessa forma, um espaço privilegiado para se pensar as possibilidades de educação e de lazer no museu MMPB, é a partir da esfera das ações educativas, entendidas aqui como práticas sociais e não apenas como procedimentos que promovam a educação. Ou seja, como atividades que possibilitem a reflexão crítica, a troca de experiências e a participação social.

Vale ressaltar ainda que a ação educativa, quando aplicada nos museus, se torna importante veículo de preservação e valorização do patrimônio, além de promover a assimilação da memória cultural, gerando a participação, através da reflexão e da criatividade. Falcão (2009), ao pormenorizar as ações que compõe as práticas educativas em museus, elenca as seguintes atividades: [...] visitas "orientadas", "guiadas", "monitoradas" ou mesmo "dramatizadas", programas de atendimento e preparo dos professores, oficinas, cursos e conferências, mostras de filmes, vídeos, práticas de leitura, contação de histórias, exposições itinerantes, além de projetos específicos desenvolvidos para comemorar determinadas datas e servir de suporte para algumas exposições. Além dos materiais educativos e informativos editados com a finalidade de servir a estas práticas, tais como: edição de livros, jogos, guias, folders e folhetos diversos, folhas de atividades, kits de materiais pedagógicos, áudio-guia

\footnotetext{
${ }^{6}$ Bianconi e Caruso (2005) apontam a educação não formal como qualquer tentativa educacional organizada que se realiza fora dos quadros do sistema formal de ensino para fornecer determinados tipos de aprendizagem a subgrupos específicos, tanto de adultos como de crianças. E entende-se como educação informal o processo permanente no qual qualquer pessoa adquire e acumulam conhecimentos, habilidades, atitudes e perspicácia através da experiência diária e contato com o meio ambiente em casa, no trabalho e no lazer, através do exemplo e de atitudes de parentes e amigos por meio de viagens, leituras de jornais e livros, vendo filmes ou assistindo a TV.
} 

e-ISSN 2016/Atual: 2525-7870 | e-ISSN 2015/2016: 2447-018X

(guia auditivo), aplicativos multimídia, CD-ROM, site institucional na internet, etc. (FALCÃO, 2009, p. 16).

Estas ações de valorização e educação patrimonial podem ser pensadas como turismo cidadão.

O turista cidadão é aquele que vivencia, usufrui e experiência as paisagens de sua própria cidade durante o seu tempo livre. Gastal e Moesch (2007) trabalham com a ideia dos citadinos viverem o estranhamento, que é sair das rotinas temporais e espaciais da própria cidade, o qual ocasiona o usufruto das paisagens com uma percepção diferenciada do seu cotidiano. Procedendo de tal modo, ao usufruir desses locais, o citadino realiza a prática do turismo cidadão, considerado como:

[...] aquele morador da localidade que vivencia práticas sociais, no seu tempo rotineiro, dentro de sua cidade, de forma não rotineira, onde é provado em relação à cidade. Turista cidadão é aquele que resgata a cultura da sua cidade, fazendo uso do estranhamento da mesma. Este estranhamento inicia no momento em que o indivíduo descobre, no espaço cotidiano, outras culturas, outras formas étnicas e outras oportunidades de lazer e entretenimento. Quando se encontra na situação de turista cidadão, este sujeito aprende a utilizar os espaços ambientais, culturais, históricos, comerciais e de entretenimento com uma percepção diferenciada do seu cotidiano (GASTAL; MOESCH, 2007, p. 65).

No MMPB essas experiências são incentivadas e estimuladas através da educação patrimonial. Desse modo, o Museu pode ser pensado como experiência do turismo cidadão a partir das ações de educação patrimonial existentes. O turismo envolve o processo de estranhamento que pressupõe o deslocamento subjetivo, em tempo e espaço, diferentes do cotidiano. Nesse contexto, o estranhamento não tem ligações com a distância percorrida, e sim com a vivência de uma experiência. Nas ações de educação patrimonial desenvolvidas no MMPB esse estranhamento é constantemente estimulado através da educação patrimonial, podendo ser um instrumento na construção da cidadania através das práticas de reconhecimento do seu lugar - a cidade - como construção histórica social, o qual faz parte, o turista cidadão.

O Programa de Educação Patrimonial do MMPB está sendo desenvolvido com a finalidade de aproximar a comunidade escolar e também a comunidade em geral desse espaço público. Desta maneira o museu contribui de forma efetiva para o fortalecimento da cidadania e para a reconstrução da memória da comunidade.

O trabalho constitui-se de um conjunto de ações educativas que tem como intuito revitalizar o espaço do museu, bem como fazer com que a comunidade escolar e local conheça e reconheça o museu como um espaço público e como um bem cultural que faz parte 
da sua história e que pode ser usufruído por todos. O projeto prevê a inserção de exposições temporárias com temas relacionados ao acervo do museu, instigando a curiosidade em relação a sua história, para isso o espaço necessita de novos expositores, de equipamentos de informática e materiais de apoio para dar subsídio às ações educativas. Dessa forma, pretendese que o Museu cumpra sua função, se constituindo em lugar de aprendizagem, lazer, reflexão e inclusão social (MMPB, 2016).

Sander (2006, p. 77) afirma que "é fundamental a criação de programas contínuos e sérios de revitalização do museu e de suas atividades. Uma alternativa é a de elaboração de um projeto de difusão do seu potencial educativo, prevendo visitas guiadas, exposições itinerantes e temporárias, sessões de cinema, seminários, cursos, oficinas".

O MMPB conta com visita guiada, geralmente monitorada por uma museóloga da instituição. A proposta é a de que o monitor seja um comunicador, fornecendo informações e explicações importantes aos estudantes ou ao publico geral. No caso do publico escolar, eles podem desafiar os estudantes, provocar reflexão a respeito de determinado assunto, permitindo que o aluno perceba que a instituição e a exposição são fontes infindáveis de saberes. Essa visita é feita com grupos de até 20 pessoas, para que seja possível acomodar os visitantes, não comprometer o acervo e não causar transtorno a visitação. A visita guiada é feita através de agendamento e dura aproximadamente 30 a 40 minutos.

O Museu possui uma cartilha pedagógica digital - Amelinha (Figura 1), a qual aborda a história do Museu da Baronesa, a relacionando com a história da cidade de Pelotas, bem como com as definições e conceitos de patrimônio que aparecem em meio à história. A cartilha está disponível no site do MMPB, no endereço http://www.museudabaronesa.com.br/cartilha.htm.

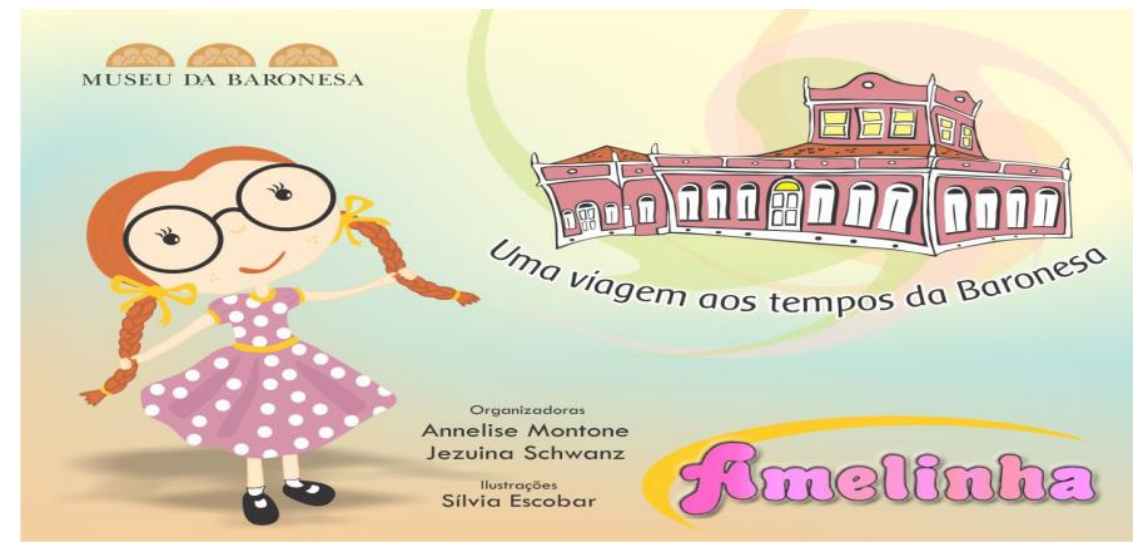

Figura 1: Cartilha Pedagógica - Amelinha

Fonte: MUSEU MUNICIPAL PARQUE DA BARONESA, 2016. 
A educação patrimonial no MMPB é realizada também através de exposições temporárias com assuntos relacionados ao acervo do museu estimulando a curiosidade em relação a sua história agregando durante meses mais valor cultural a exposição de longa duração. O Museu já abrigou diversas exposições temporárias que são montadas para permanecer um determinado período entre as demais peças do acervo. Dentre elas, podemos citar a exposição "Carnavais D'outrora" (Figura 2), cuja finalidade era contar, através de recortes de jornais e objetos, o carnaval da cidade de Pelotas nos anos de 1913 a 1930 . O convite foi divulgado nos principais meios de comunicação, como jornal local e redes sociais.

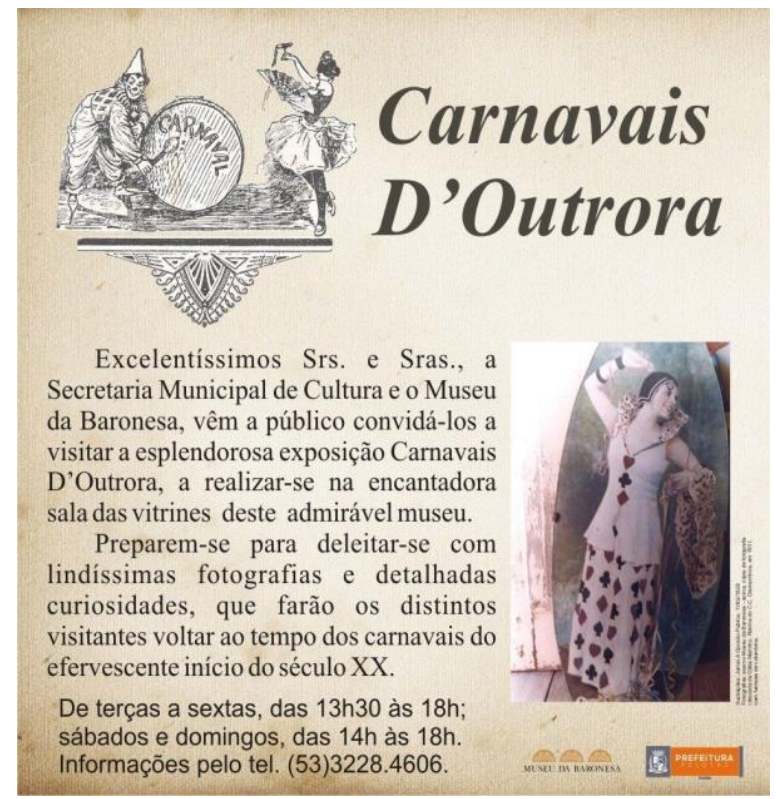

Figura 2: Convite para exposição Carnavais D’outrora.

Fonte: www.facebook.com.br/museubaronesa.secult

O parque é utilizado pela comunidade também nas áreas educativas e culturais, também consideradas práticas de lazer, como os projetos “Trilha Ecológica no Parque da Baronesa", "Arte aos Quatro Ventos", entre outros, objetivando levar às comunidades dos bairros diversas manifestações culturais e, ainda, conhecer o bosque sob o olhar da educação patrimonial e ambiental. Desse modo, tanto o Parque quanto o Museu podem ser considerados um patrimônio da cidade, bem como espaço de lazer, local de aprendizagem e troca de conhecimento.

Algumas ações são realizadas no intuito de aproximar os moradores da cidade ao MMPB, entre elas, citamos o "Dia de Passe Livre" (Figura 3), no qual a visitação ao Museu ocorre gratuitamente; "Domingo no Parque", que a partir do patrocínio da Prefeitura de Pelotas, ocorrem apresentações de teatro, bandas locais e a presença do Grupo Tholl. 

e-ISSN 2016/Atual: 2525-7870 | e-ISSN 2015/2016: 2447-018X

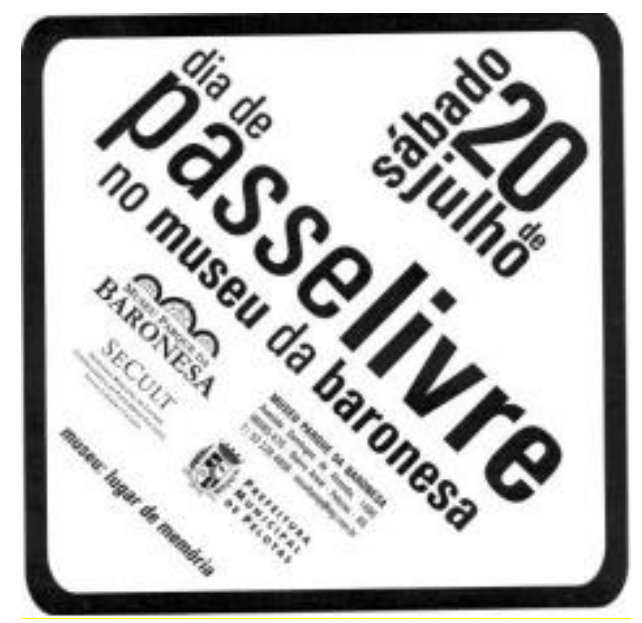

Figura 3: Material de divulgação do dia do passe livre no museu.

Fonte: MMPB, 2016.

Também existe no MMPB alguns trabalhos de valorização patrimonial como o projeto Fazendo Musica no Museu (Figura 4), que acontece desde 2010. Por meio deste projeto o MMPB busca proporcionar a comunidade e aos visitantes, gratuitamente, outra forma de aproxima-los dos espaços do museu, através da musica que se enquadre no período histórico em que o museu se insere. Pode-se dizer que este projeto também tem a finalidade de valorizar e promover os artistas de Pelotas e região proporcionando um lugar adequado e diferenciado para mostrarem sua produção cultural.

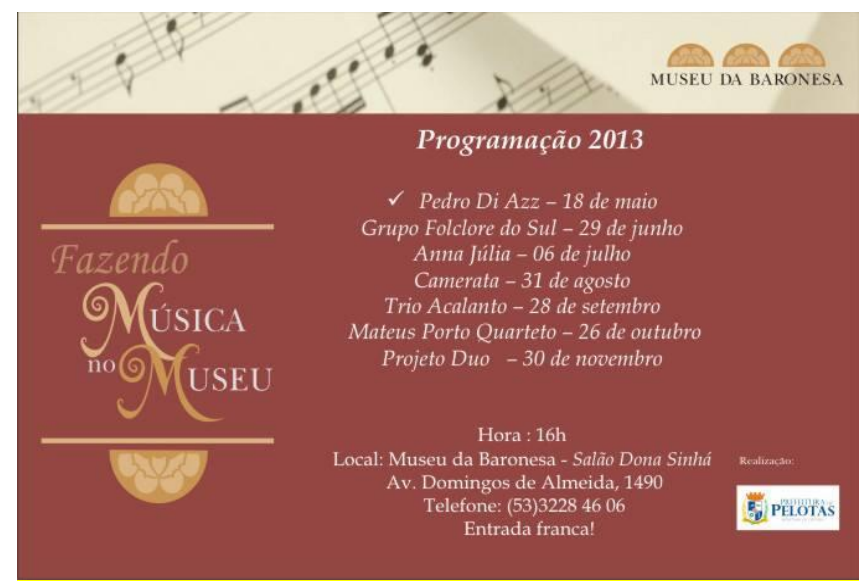

Figura 4: Programação do Fazendo Musica no Museu de 2013

Fonte: www.facebook.com/museubaronesa.secult 
Além dessas atividades, o Museu também abriga eventos importantes da cidade, como o Piquenique Cultural (Figura 5), que é um movimento multiartístico que ocorre, desde 2010, em locais diferentes, como praças e parques da cidade.

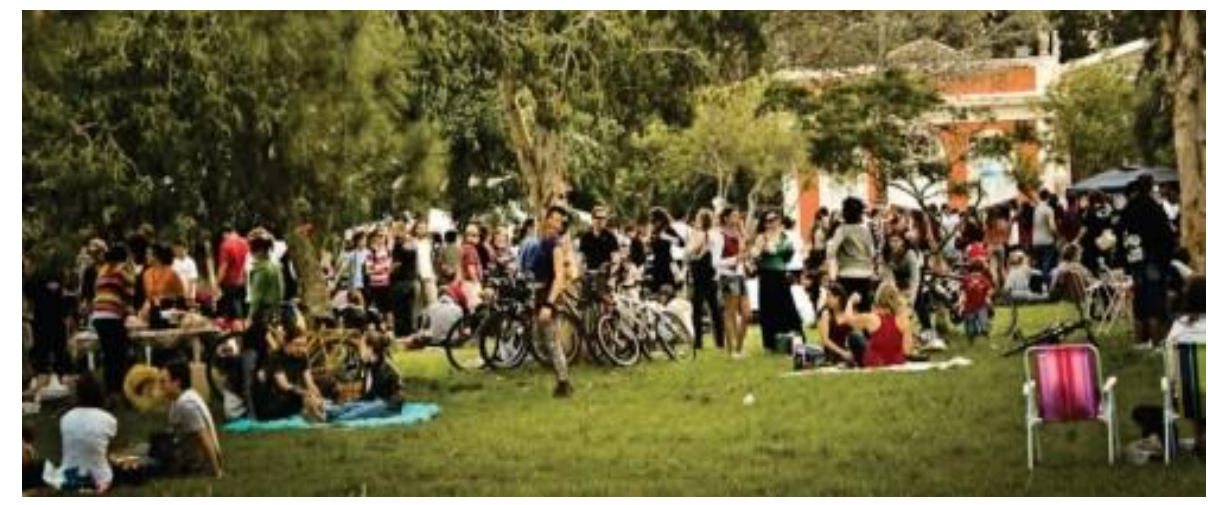

Figura 5: Piquenique Cultural no Parque da Baronesa

Fonte: http://www.ecult.com.br/noticias/piquenique-cultural-tera-16\%C2\%AA-edicao-na-praca-da-rodoviaria-de-pelotas

O museu cobra entrada e esse valor é revertido para manutenção do museu, promoção das exposições, produção de folders e melhorias no funcionamento do local. O ingresso ao museu é gratuito para os estudantes da rede municipal e estadual de Pelotas e região, também para grupos assistenciais, pessoas deficientes e crianças até 12 anos. A meia-entrada atende estudantes de escolas particulares acima de 12 anos, universitários, professores e idosos acima de 60 anos mediante documento de identificação. O museu funciona de terça a sexta das $13 \mathrm{~h} 30$ às $18 \mathrm{~h}$ e sábados, domingos e feriados das 14h às 18h (MMPB, 2016). Entretanto o acesso ao parque e a área verde ao redor do museu é gratuito e pode ser feito a qualquer horário do dia.

Um dos meios de divulgação e de educação utilizado pelo MMPB é um folder (Figura 6) que conta a história da cidade e da família. Ele pode ser encontrado nos postos de informações turísticas e secretarias da cidade além de recebê-lo ao visitar o museu. 

e-ISSN 2016/Atual: 2525-7870 | e-ISSN 2015/2016: 2447-018X
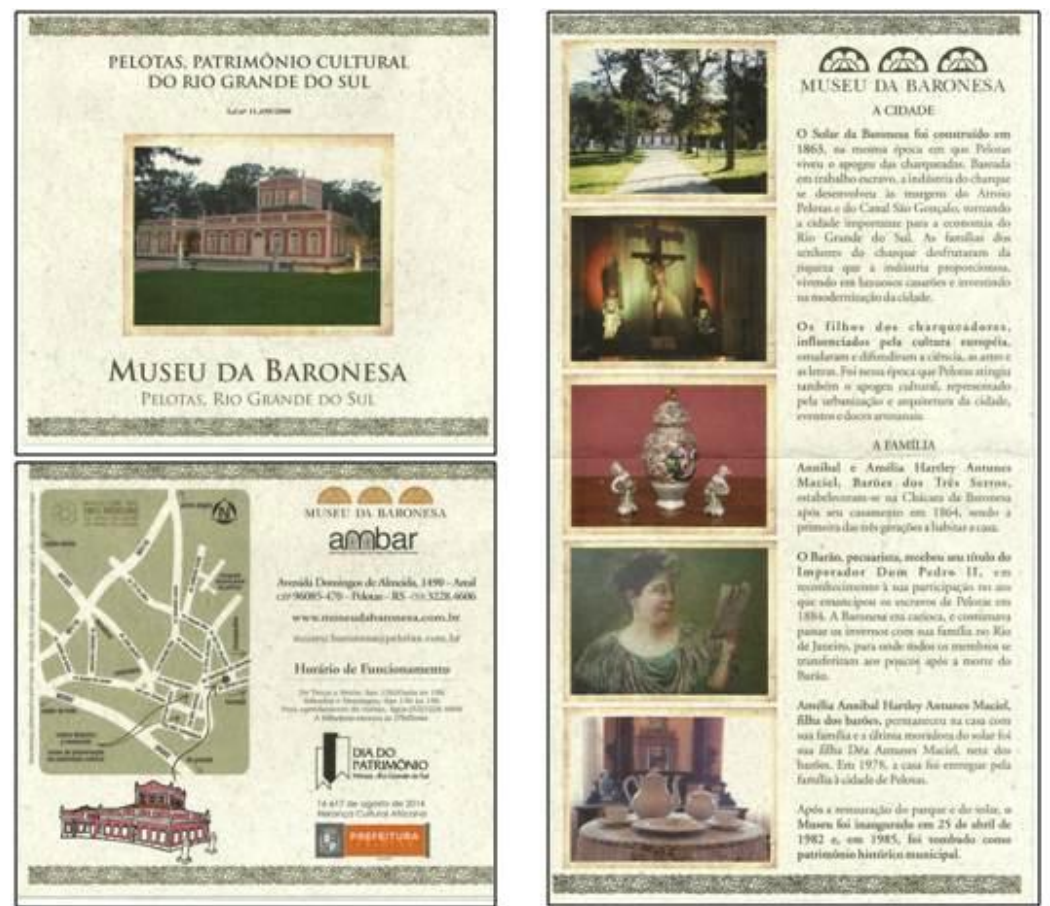

Figura 6: Folder de Divulgação do Museu Municipal Parque da Baronesa.

Fonte: Acervo pessoal das autoras

A ação educativa extramuros desenvolvida pelo MMPB caracteriza-o como um museu que busca uma maior interação entre cultura e cidadão, incentivando reflexões e ações para a formação de um museu que vá além de seus espaços físicos e funções técnicas de salvaguardar e expor material, além de atuar como um espaço que visa representar culturalmente o povo pelotense, pois,

[...] dar oportunidade de acesso, mas principalmente voz, aos excluídos culturais, é fazê-los interagir de forma significativa com a arte e o museu, de maneira a incorporá-lo ao seu cotidiano, como estopim de uma transformação da consciência critica no perceber, julgar e agir no mundo (CHIOVATTO, 2010a)

As práticas educacionais na sociedade possuem a função vital de transformar, mudar, conscientizar. Dessa forma, é importante que haja por parte dos museus uma efetiva ação de educação patrimonial, um incentivo ao diálogo através do qual se possa oferecer ao publico uma contextualização histórica.

Essa inter-relação construída a partir de uma iniciativa educativa possibilita, sobretudo, uma nova perspectiva de ação museológica, onde é possível achar arte fora do universo físico do museu. Desta forma, os objetos presentes no museu não extinguem sua relevância no próprio corpo físico ou no espaço do museu, mas apontam para fora de si, para o mundo, para a vida vivida na sociedade (CHIOVATTO , 2010b) . 
O turismo é uma atividade que envolve questões histórico-sociais que pressupõem deslocamentos de indivíduos em tempos e espaços diferentes daqueles dos seus cotidianos, que, por sua vez, possibilitam o afastamento concreto e simbólico do dia a dia. Segundo Gastal e Moesch (2007, p. 12) "[...] o Turismo se constitui em um fenômeno sociocultural de profundo valor simbólico para sujeitos que o praticam". Simbólico, por seus valores de uso e afetividade que ocasionam ao indivíduo sensações de surpresas, sentimentos e comportamentos, levando-os a (re)pensar, (re)ver e (re)avaliar não só o momento vivenciado, mas também a vida.

Desse modo, o Museu Municipal Parque da Baronesa pode ser pensado como uma experiência de turismo cidadão a partir das ações de educação patrimonial desenvolvidas. $\mathrm{O}$ turismo envolve o processo de estranhamento que pressupõe o deslocamento subjetivo, em tempo e espaço, diferentes do cotidiano. Nesse contexto, o estranhamento não tem ligações com a distância percorrida, e sim com a vivência de uma experiência.

Nas ações de educação patrimonial que o MMPB vem desenvolvendo, esse estranhamento é constantemente estimulado, transformando, assim, a comunidade local em visitantes na sua própria cidade.

Turismo cidadão é, para além da atividade turística, uma expressão cidadã, uma forma de conhecer e compreender a cidade. Assim turismo cidadão é um fenômeno onde o habitante sensibilizado desenvolve um relacionamento diferente com o local onde mora no seu tempo de lazer, que exposto ao estranhamento, utilizando-se dos fixos e fluxos da cidade com percepções diferentes da cotidiana e apropriando-se da cidade por meio da experiência vivida.

Segundo Gastal e Moesch (2007, p. 60), para o turista cidadão “[...] os fixos que compõem a cidade deixam de ser desconhecidos. O território torna-se familiar e, nele e com ele, constrói-se relação de pertencimento e identificação, pois se passa a compartilhar seus códigos e, de posse dos mesmos, a situar a própria subjetividade em relação aos fixos presentes no urbano".

\section{Considerações Finais}

Os museus são importantes meios comunicadores e educadores, local de descoberta para os turistas cidadãos.

O MMPB viabiliza diversas ações de educação patrimonial, tais como a visita guiada monitorada, a cartilha pedagógica digital - Amelinha, exposições temporárias, práticas de lazer, entre outras que incentivam o turismo cidadão, que é para além da atividade turística uma expressão cidadã, uma forma de conhecer e compreender a cidade. Tais ações 

e-ISSN 2016/Atual: 2525-7870 | e-ISSN 2015/2016: 2447-018X

desenvolvidas pelo MMPB possibilitam que onde o turista cidadão desenvolva um relacionamento diferente com o local onde mora no seu tempo de lazer, que exposto ao estranhamento, utilizando-se dos fixos e fluxos da cidade com percepções diferentes da cotidiana e apropriando-se da cidade por meio da experiência vivida.

Dessa maneira, percebe-se que as ações educativas não podem ser vistas apenas como técnicas que se encerram em si e sim como ações que podem contribuir para despertar a consciência do indivíduo e na formação de cidadãos críticos e conscientes. O museu é um instrumento que vem reforçar a identidade das comunidades ao contribuir para salva guardar um patrimônio estimado por todos.

Por fim, sem a intenção de concluir, o turista cidadão apodera-se da cidade por meio da experiência vivida. "Turismo seria menos o percurso no espaço, para tornar-se um percurso por tempos-espaços, em especial culturais, diferentes daqueles a que se esteja habituado, com ênfase nas vivencias e experiências" (GASTAL e MOESCH, 2007, p. 37).

\section{Referências Bibliográficas}

ALENCAR, Vera. M. A. Museu-educação: se faz caminho ao andar. 1987.201f. Dissertação (Mestrado em Educação) - Departamento de Educação, PUCRJ, Rio de Janeiro, 1987.

BIANCONI, M. Lucia, CARUSO, Francisco. Educação Não-Formal. Ciência e Cultura, vol.57 n. 4 São Paulo Out./Dez. 2005.

BRUNO, Maria Cristina O. Museus Brasileiros: um universo a ser conhecido. In ALMEIDA, M. C. B. (org.). Guia de Museus Brasileiros. São Paulo: Edusp, 1996 (p.9-13).

CHIOVATTO, Milene. Ação extramuros: diminuindo barreiras. In: Percorrer e Registrar: Reflexões sobre a ação educativa extramuros da Pinacoteca de São Paulo. São Paulo, 2010.a

CHIOVATTO, Milene. Museu, imaginação e formação dos sujeitos: a experiência da Pinacoteca do Estado de São Paulo. São Paulo, 2010.

FALCÃO, A. Museu como lugar de memória. Salto Para o Futuro, ano 19, n. 3, p. 5-9, maio 2009.

GASTAL, Susana. MOESCH, Marutschka. Turismo, políticas públicas e cidadania. São Paulo: Aleph, 2007.

HERMETO, M; OLIVEIRA, G. D. Ação educativa em museus: produção de conhecimento e formação para a cidadania? In: AZEVEDO, F. L. M.; CATÃO, L. P.; PIRES, J. R. F. (Org.). Cidadania, memória e patrimônio: as dimensões do museu no cenário atual. Belo Horizonte: Crisálida, 2009. p. 89-107

HORTA, Maria de Lurdes Parreiras. Educação Patrimonial. Comunicação apresentada na Conferencia Latino Americana sobre a preservação do Patrimônio Cultural. Jun, 1991. 
HORTA, Maria de Lurdes Parreiras. Educação Patrimonial. Comunicação apresentada na Conferencia Latino Americana sobre a preservação do Patrimônio Cultural. Jun, 1991.

MONTONE, Annelise Costa. Representações da vida feminina em um acervo de imagens fotográficas do Museu da Baronesa, Pelotas/RS: 1880 a 1950. 2011. 197f. Dissertação (Mestrado em Memória Social e Patrimônio Cultural) - Programa de Pós-Graduação. Instituto de Ciências Humanas. Universidade Federal de Pelotas.

MUSEU MUNICIPAL PARQUE DA BARONESA. Disponível em: http://www.museudabaronesa.com.br/cartilha/. Acesso em: 26.07.2016.

PAULA, Débora Clasen de. Da mãe e amiga Amélia: cartas de uma Baronesa para sua filha (Rio de Janeiro - Pelotas, na virada do século XX). 2008. 264f. Dissertação (Mestrado em História) - Unisinos, São Leopoldo, 2008.

SANDER, Roberto. O museu na perspectiva da educação não-formal e as tendências políticas para o campo da museologia. 2006. 101f. Dissertação (Mestrado em Educação) Universidade de Passo Fundo, 2006.

SCHWANZ, Jezuina Kohls. A Chácara da Baronesa e o Imaginário Social Pelotense. 2011. 201f. Dissertação (Mestrado em Memória Social e Patrimônio Cultural) - Universidade Federal de Pelotas, Pelotas, 2011.

VASCONCELLOS, Camilo de Mello. Turismo e Museus. São Paulo: 2006.

Diário Popular, 03.07.1978.

Correio do Povo, 27.04.1982. 